\title{
Intelligent, parametrically sustainable architectural design
}

\author{
V. Vermesan ${ }^{1} \&$ U. P. Flueckiger ${ }^{2}$ \\ ${ }^{1}$ Faculty of Architecture and Fine Art, NTNU, Norway \\ ${ }^{2}$ TTU College of Architecture, Texas Tech University, USA
}

\begin{abstract}
Retrofitting the many unsustainable built environments created in recent decades is a pressing urban and suburban design challenge, with sustainable architecture seemingly a common thread. Parametric and generative design is considered a current trend in architectural design. The aim of this paper is to investigate the potential for applying parametric design during the early conceptual stages, in which architecture and urban design overlap, in order to achieve a sustainable style of design. Using a parametric model, the evolutionary process can be accelerated by computer algorithms, allowing many more otherwise expensive and timeconsuming variants and evaluation criteria to be considered, as well as offering more creative solutions to design challenges that are too complex to be solved by human intuition. We advocate the concept that comfort, in terms of environmental conditions, is an objective worth pursuing for suburbs everywhere, while designing in partnership with nature helps to address this quality of life factor, which is otherwise difficult to measure. A suburban area in Amarillo, West Texas, was selected as the case study location because it is representative by being rich in architecture and natural resources, while Amarillo and the surroundings have also undergone some urban and suburban transformations in the past. Intelligent parametrically sustainable design involves replicating the principles found in nature in order to create interaction between it and the built environment, with the aiming of finding the optimum solution through parametric modelling, analysis, simulation and optimization, and ultimately with the intention of assisting architects in the decision-making process.

Keywords: parametric design, suburbs, eco-sustainable architecture, differentiation, evolutionary design, optimization.
\end{abstract}




\section{Introduction}

How to retrofit the many existing unsustainable built environments created during the last decades is an important urban and suburban design challenge. Many authors [1-7] have reported on what has gone wrong with suburban development in the last decades and how to reverse the situation, involving processes that span from small changes to erasing it completely. Lukez [1] proposes design actions as part of an "adaptive design process" in order to transform poorly designed suburbs into more livable, vital sustainable communities with character and identity. The solutions to the problems and the designs involved may vary from site to site and from country to country and their individual cultures, but sustainability affects us all because it is a global problem to resolve.

Architectural sustainability comprises three strands: environmental, economic and cultural. Recently, making cities and suburbs greener, as well as harmonizing architecture with nature (eco-architecture), has received much attention [8-11]. This paper addresses the evolution of environmental sustainability through parametric design. Again, environmental sustainability has many different meanings to different people and the early approaches dealt primarily with reducing energy consumption. Other approaches are mentioned in, where builders put solar panels on large suburban houses and claim they are "green" or "sustainable", but without considering the energy consumption that such large structures require. The processes to achieve environmental sustainability are more complicated than energy savings, often involving non-measurable and conflicting parameters, which make it necessary to employ complex algorithms in order to find a balance.

Priorities must be established in each particular situation, but in this paper we advocate the concept that comfort in terms of environmental conditions is an objective worth pursuing for suburbs everywhere, regardless of how small or large communities are, and that designing in partnership with nature helps to address this otherwise difficult-to-measure quality-of-life factor. Nature is often already there in the suburbs, so unlike cities there is no actual need to bring nature into the suburb. However, just being there is not enough in order to experience nature and this is where architecture comes into the picture. The interpretation of environmental sustainability we have taken in this paper is that the design of suburban architecture must not only minimize the environmental dangers, but also strive to maximize what contact with nature can bestow on us - maximize the comfort that communicating with nature entails.

How are the suburbs designed so that nature affects both individual buildings and the built environment in order to maximize the benefits nature can have? It is our belief that, in the case of suburbs, the architecture and the urban design must overlap during the early stage of the conceptual design in order to achieve an optimum of sustainability. In other words, the two need to be addressed together, in a continuous improvement process.

In this context, the aim of the paper is to investigate the potential for applying generative and parametric design [12-14] during the early conceptual stages in order to achieve this sustainable style of suburban design based on optimization 
of comfort. We look in particular to those factors to offer differentiated responses to the diversity of environmental parameters and to cope with the multi-objective optimizations that need to be done in order to select the right decisions in this sense.

Architecture is a very complex adaptive system, where improvement happens through an evolutionary process. This iterative cycle of differentiation and selection occurs naturally when architects refine their designs by continuously redesigning. Using a parametric model, the evolutionary process can be speeded up by computer algorithms, allowing many more otherwise expensive and timeconsuming variants and evaluation criteria to be considered, as well as more creative solutions for design challenges that are too complex to be solved by human intuition.

Small changes to a design can have large and unexpected effects and the discovery of unintended consequences of early decisions often takes place late in the design process. This is especially true for comfort conditions, both indoors and outdoors. Correcting them in the late design stages often is expensive, if at all possible, so analysing and predicting comfort conditions during the early design is a better alternative.

The main objective of the paper is to determine and quantify the factors that influence the shape and size of the suburb layout and the buildings in order to maximize the visual and the thermal comfort for the users. By visual comfort, we understand natural daylight and the aesthetic of the outside environment in partnership with nature. Designing in contact with nature focuses on the meaning of the suburb and the buildings' form and employing algorithms and principles inspired by nature does indeed give meaning. By thermal comfort, we understand parameters giving the sense of comfort, such as solar heating, cooling and ventilation, which together with natural lighting are preferred by many architects because they derive from bio-climatic awareness.

With this in mind, making a suburb more attractive, transforming a low quality suburban development into a more sustainable one or designing a suburb that is in partnership with nature and its surroundings all call for intelligent solutions. A habitat that is based on architecture and reuse of natural resources is central to any of these processes and this is where generative and parametric architectural concepts come into play.

Today, most people live and work in environments more suburban than urban and more vegetal than architectonic. Thus, the boundary between architecture and landscape architecture becomes less strict, because suburban is mainly concerned with landscape, streets, parks and backyards. Architects need to understand settlement patterns that affect the building architecture and at the same time need to be able to design new patterns in order to change the repetitive and sometimes monotonous and uninteresting nature of today's suburban landscape. New solutions encompassing qualities such as differentiation and attractiveness are needed, not only at the structural or building level, but also in the suburban context.

Spatial arrangement is a fundamental aspect of architecture that affects the social performance of buildings and this cannot be truer than in the case of suburbs. Hence, the suburban neighbourhood and its layout must be analysed and well 
understood before any building design can start. Thus, outdoor spatial analysis is an integral part of the overall architectural design process.

\section{Location}

A suburban area in Amarillo, West Texas, was selected to act as the case study location. Amarillo is the 14th most populous city in the state of Texas and has been chosen as being representative, rich in architecture and natural resources.

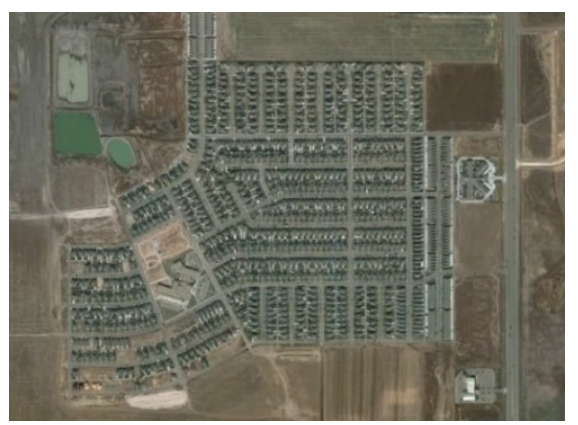

Location information:

Address: Amarillo, Texas, USA

Latitude: 35.1397

Longitude: -101.9468

Figure 1: Amarillo location (Google Earth).

In addition, it has already undergone some urban and suburban transformations. In the 1960s, urban renewal razed the downtown districts completely and destroyed much of the fabric in favour of explosive development of the suburbs. This trend changed in the 1980s with the goal of sustainable development.

The location is a district in south-west Amarillo and is presented in fig. 1. The location is delimited by a highway to the east with a residential road and a lake to the west, which makes it a good candidate to demonstrate how to develop architecture to interact well with its natural environment and respond to nature's conditions.

We started with initial configurations based on the context of the traditional architecture and natural resources, which gives a good start, because the architecture that already exists has been developed and adapted to the climate for many years. These have been input for further analysis and simulations, taking into account the main environmental factors of the living space, i.e., sunlight, wind, and temperature, in order to generate more variations of both suburban and building form.

The simulations covered solar access with sunlight hours, comfort shade benefit, wind patterns, daylight levels and glare. The findings and results were analysed to see how they influence the district form in terms of density of sites, pattern, orientation and also the building form in terms of type of foundation, plan, cluster, orientation. The goal was to achieve the optimum sustainable suburban transformation with the objective of comfort in mind. A comparison analysis was carried out between the resulting case and the initial case. Future recommendations were drawn based on the findings and results. 
A further investigation was performed, inspired by [15-18] in order to gain an understanding of the wider picture of climate, traditional architecture, culture and natural resources in West Texas.

The general housing developments in West Texas typically consist of flat-faced one story ranch-style housing. The Western lifestyle is predominant, not necessarily in the strict sense of the "cowboy" style, but also in the sense of freedom. A too-tight or close-built environment would quickly be seen as negative. The culture is very mobile and the automobile is a strong symbol. Therefore, large residences and access for cars are important in order to get contemporary housing accepted in this area.

An abundance of wide open land in West Texas made most homeowners want their own piece of property. To create successful housing in a suburban context, the need for private space must be addressed. In addition, quietness is essential. The whole suburban concept is built upon the need to escape the city. This put some extra pressure on suppressing noises to create a silent atmosphere both indoors and outdoors. In addition to sound, attention must be given to visual effects and the aesthetic of the outdoor environment, in order to compensate for the lack of socialization. This is not necessarily specific to this location, but rather a characteristic of many contemporary suburbs, built as a collection of independent buildings, having little in common with the adjacent buildings, sites or district. There are many disadvantages of building in such an ad hoc manner and creating a disconnected environment.

The built context has elements of the agriculture industry. Current housing styles are built with little or no consideration of solar orientation or climate factors.

The natural context of the region is characteristically flat farm or ranch land and grass fields. Further consideration needs to be given to protect the community from wind, as well as to take advantage of it. High winds are a part of the climate in West Texas and there is a need to protect the buildings. Most of the year, the region has a sunny climate over 280 days of sunshine an average year. Conservation of natural resources is important.

These real conditions summarize the research and investigation of the cultural and psychological aspects, the built environment and the natural resources, and include inspections on location in order to take photographs, gather material and, when possible, even talk to local people. These conditions can also be easily found in some European countries.

Although it is necessary to select an actual location in order to perform a simulation using local climate data, it is important to emphasize that the methodology and the processes involved can be applied to districts and neighbourhoods anywhere. The parametric model can be adjusted according to any location on the globe.

\section{The parametric suburban model}

Basically, the parametric model has been constructed by considering the spatial context parametrically divided into subdivisions, with the existing roads as the division elements. A number of points are distributed on each subdivision and, as 
points are "sites", there is an upper limit for this number, whose value depends on local regulations. During the first experiments, the distribution of points was random and a grid was used as the existing topology. It then moved to more innovative mathematical algorithms - points along a path ("road"), in order to obtain different patterns and geometries. The point distributions were then inputted to Voronoi diagrams in order to partition the subdivisions.

In this paper, we start from a more innovative topology, where points are agents moving within the boundary of the location based on a predefined set of rules. The rules reflect interaction such as cohesion, separation and alignment. Complex behaviour can be programmed based on swarm intelligence algorithms. Natural resources such as lakes, forests or other green spaces are considered attractors, while highways are the opposite. The location is thus modelled as an organism living its own life. This can be best visualized by real time simulations, i.e., piping the movement of such an agent-based system to a Voronoi component.

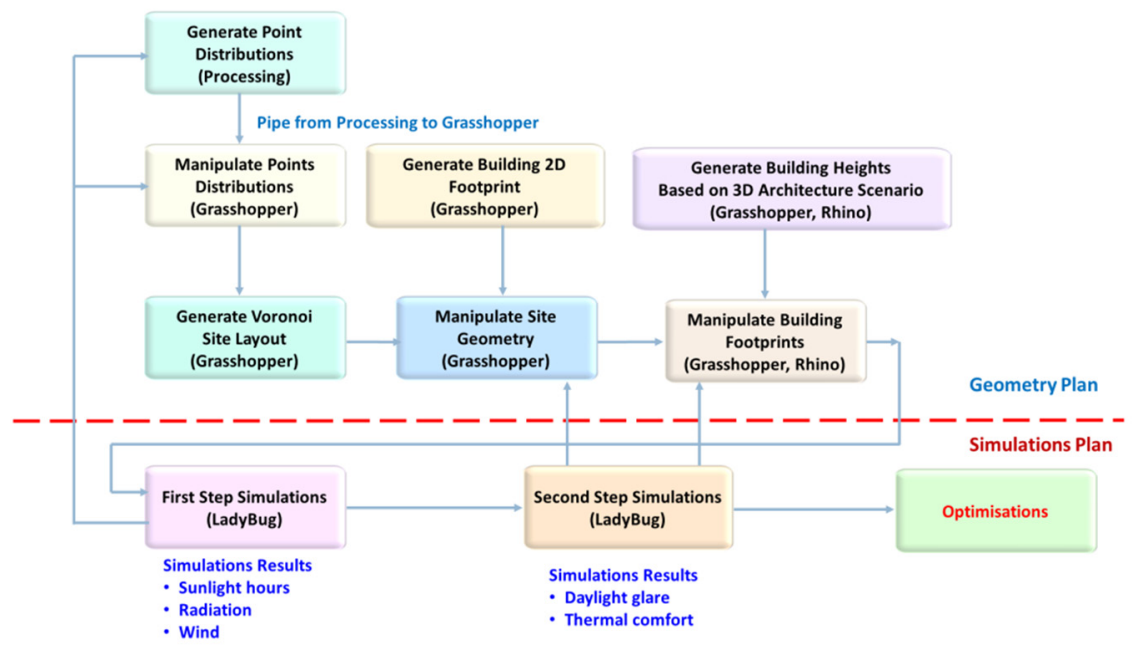

Figure 2: Simplified flow diagram.

Voronoi diagrams provide a means of naturally partitioning space into sub regions to facilitate spatial data manipulation, modelling of spatial structures, pattern recognition and locational optimization and have applications in many disciplines, computer science, biology, architecture, etc. [19]. Examples of Voronoi diagrams can be also found in nature, i.e. dragonfly wings, giant lily, giraffe body. The Voronoi diagram is used in architecture for space partitioning due to many advantages: it gives a consistent definition of the spatial relationships between sites; the geometry of the sites adapts to the distribution of points and the properties are valid in any dimension so that they are dynamically reconfigurable - we can add or delete sites, or reconstruct a site.

The buildings were then parametrically generated on the Voronoi sites. The building structure is defined by the size of the site area and heights, given by the number of floors. The outcome of this process - a set of possible concrete spatial 
configurations - is the input for environmental exploration, having visual and thermal comfort as the objective. The initial generated structure is optimized iteratively both in geometry and density (by manipulating the distribution of points). The flow is presented in fig. 2 .

\section{Visualization, analysis and simulation}

Temperature, wind and daylight are the major factors affecting human comfort. It is, therefore, essential to understand climate in relation to these factors. To this end, various visualizations and analyses were conducted, followed by simulation. The platform is an integrated design parametric environment bringing together conceptual massing and environmental analysis using Rhinoceros 3D software, parametric Grasshopper plugin and Ladybug plugin [20]. The climate data was imported from EnergyPlus Weather files (.EPW) (from DOE website) developed as part of the Ladybug and Honeybee development. The spatial data was imported from OSM files (Google Maps and Open Street).

Figs 3, 4 and 5 show visualizations and analysis without the geometry: sky condition for Amarillo during the cooling period (fig. 3); the sun-path and sunpath vectors (fig. 4); wind speed and profile (fig. 5).

Radiation is an important factor to consider in thermal comfort, in addition to energy performance studies. We get high temperatures because the energy from the sun also provides heat due to the level of radiation. The light we receive from the sun, its radiation and illuminance combine to give levels of daylight. Designing architecture with good sense of temperature, wind and daylight in mind greatly impacts the sense of comfort.

Radiation analysis at the layout scale provides valuable information about where to increase density, whereas it helps to determine the orientation or whether to take action on the exposed façade at the site level. The results impact differently at different scales, while the impact seems to decrease with the scale.
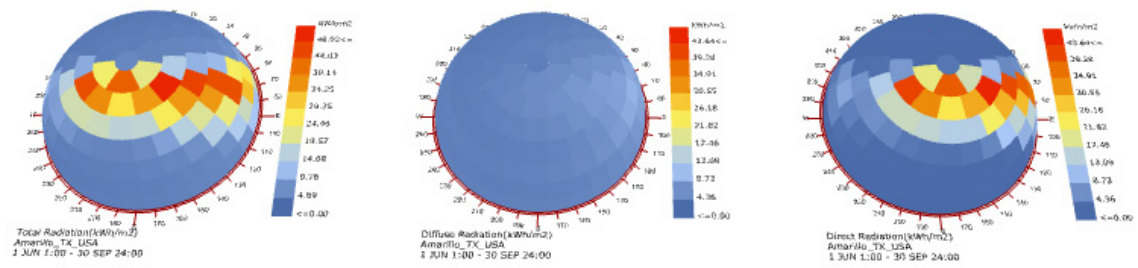

Figure 3: Sky condition for Amarillo during cooling period (June to September).

Ladybug calculates the amount of radiation for different sky patches of the sky dome and colours the sky patches based on the result; the graphic in fig. 3 gives an overall understanding of the sky condition during the selected periods of the year. Sun-path is another useful diagram for environmental analysis as it shows the connection between the sun-path and hourly weather data (fig. 4). 


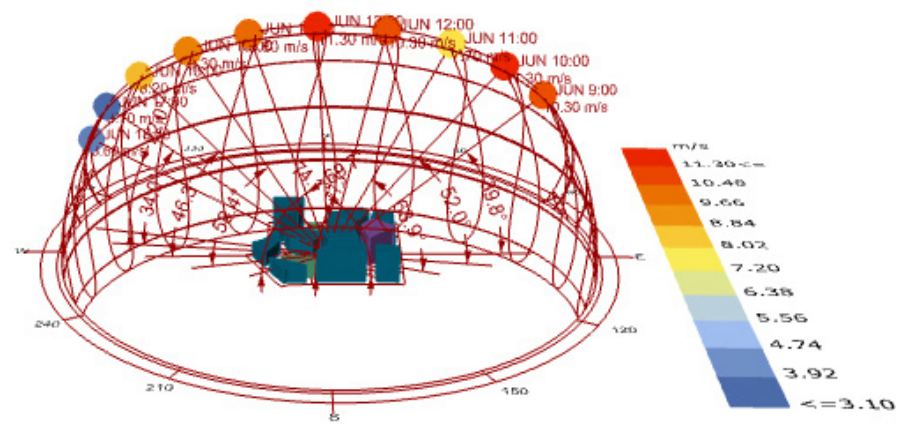

\footnotetext{
Sun-Path Diagram - Latitude: 35.23

Hourly Data: Wind Speed ( $\mathrm{m} / \mathrm{s})$
Amarillo_TX_USA
}

Figure 4: The sun-path.

Wind direction and speed are relevant for suburban and urban design, not only in terms of comfort but also other purposes, such as a natural ventilation design flow through a building. For the purpose of comfort, it makes sense to look at both wind and temperature; a range between 18 to 20 degrees Celsius is normally considered to be an ideal temperature. Comfort analysis requires a very large volume of data, such that filtering out temperatures below and above this range would greatly narrow the data to be analysed.
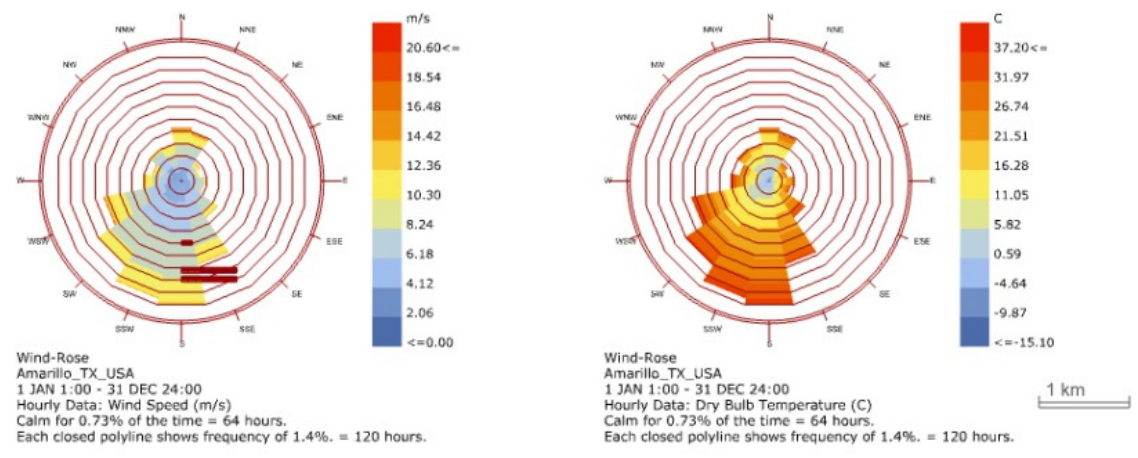

Figure 5: Wind direction and temperature.

The illustrations of monthly and yearly wind rose diagrams in fig. 5 show the prevailing wind directions in the winter and summer. It seems that wind mainly comes from the south and southwest. The wind profile shows there is always more wind at higher levels than in a suburban environment. At relatively low heights, however, wind-blowing at over $6 \mathrm{~m} / \mathrm{sec}$ can be a problem. Wind speed at ground level can also affect comfort. Wind influences the building glazing percentage and other features of the façade design, material and construction process, although wind has the most impact at the suburban scale, i.e., with geometries. 
High winds in Amarillo are a known difficulty of the area. They can damage buildings, strip away valuable topsoil of the agricultural land, and affect the sense of comfort. A natural solution to this problem is wind barriers with dense forestry or planting, which can be incorporated in the parametrical model. Simulations conducted with wind data help in identifying the prevailing wind directions. The height of the wind barrier can be optimized based on the desired length of wind shadow and aesthetics.

The simulation geometry model is shown in fig. 6 . The simulations consider both the design geometry as well as the context: boundary of one sample site, a sample building, boundary of the context ground, the building context, and the green space context.
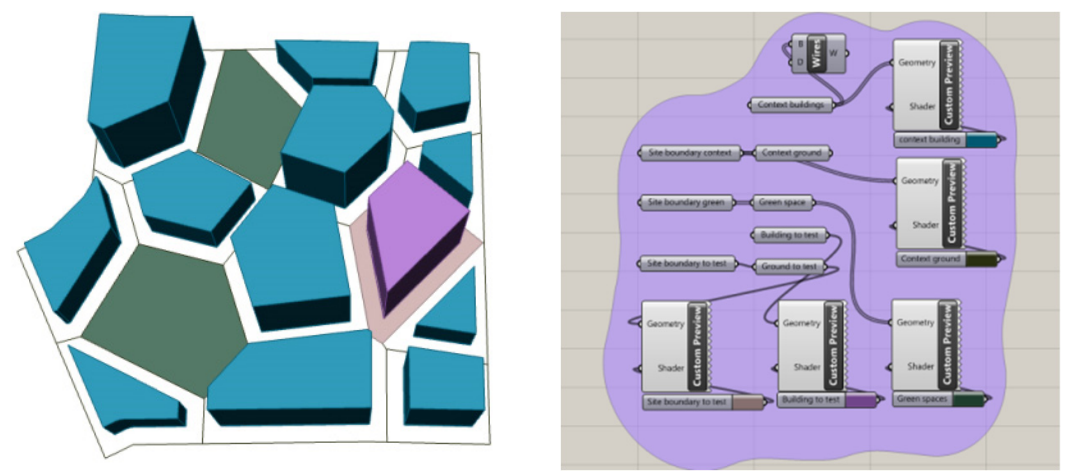

Figure 6: The simulation geometry model.

The sun-path component allows filtering the sun positions, based on desired conditions. In fig. 7 an example is shown, plotting the sun-path for hours of the year when the temperature is more than $18^{\circ} \mathrm{C}$.

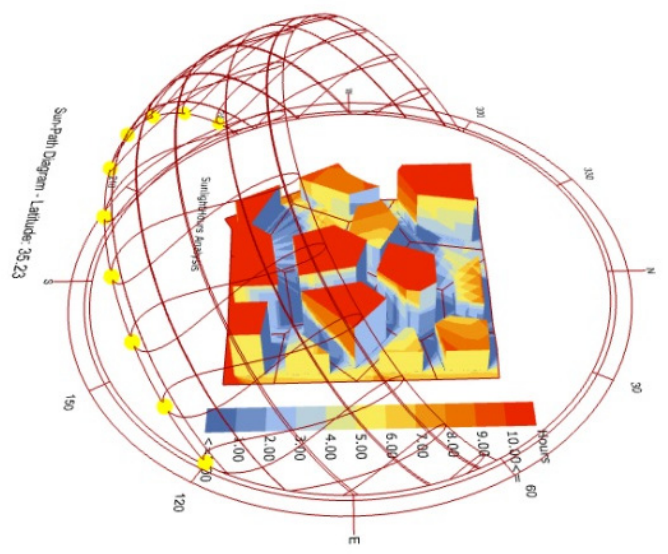

Figure 7: Radiation with sun path. 
Including conditions on temperature and radiation can considerably speed up the process of orientation and shading design.

Orientation simulations explore the relationships between the amount of solar radiation or sunlight hours, and the orientation of the building. Fig. 8 shows the result of the simulation on one sample building, where the inputs are the sample building geometry and the building context, and the output is a coloured mesh. The orientation of the building in fig. 8(a) indicates that it receives the maximum amount of radiation during Amarillo's heating period. The Ladybug orientation component can run with different time periods, range and divisions of the angles. Fig. 8(b) shows the same with the whole building geometry as input.

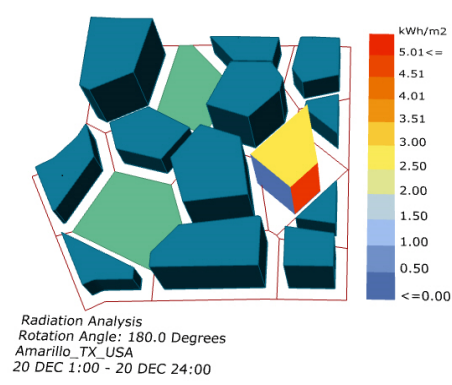

(a) With orientation simulation

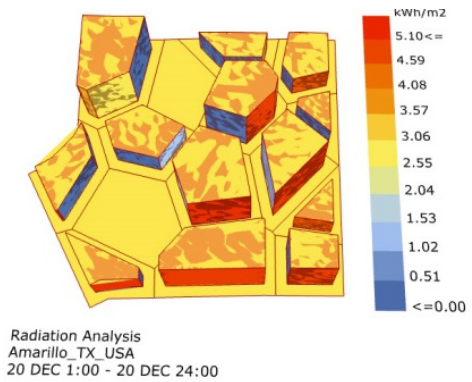

(b) With all buildings geometry

Figure 8: Radiation analysis with orientation simulation.

Shading is extremely important and appropriate shading strategies must be incorporated into the design. Fig. 9 shows an example of the shading design process based on temperature and wind speed during the cooling period (June) and location of the sun provided by the sun-path component.

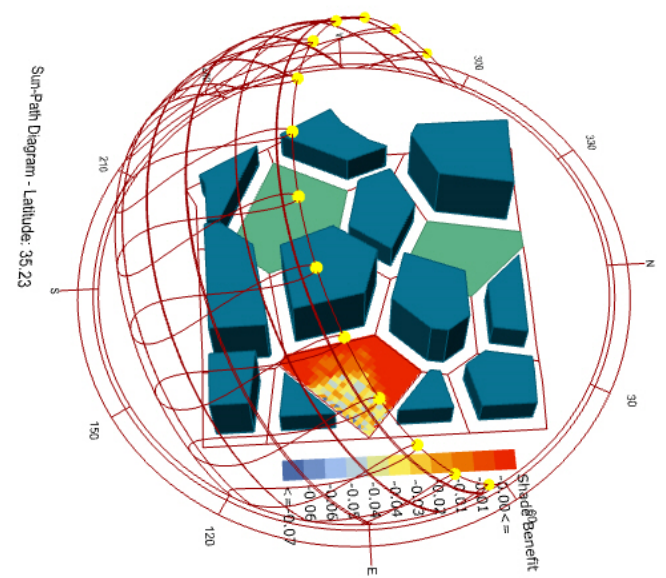

Figure 9: Shade analysis. 
The resultant sun-vectors can be used to design the shading. The $3 \mathrm{D}$ sun-path shows the hours of the year that the temperature is more than $18^{\circ} \mathrm{C}$.

The sun-path component allows to filtering the sun positions, based on desired conditions. Conditional inputs can easy the process of shading design.

Simulations using Galapagos have been conducted in order to obtain optimum building forms related to radiation. Fig. 10(a) shows an example of form optimization in terms of building shape to maximize the amount of solar radiation during the heating period, while fig. 10(b) has the same objective but in terms of size and orientation.

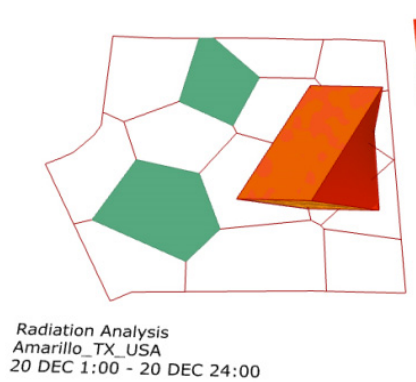

(a) Shape

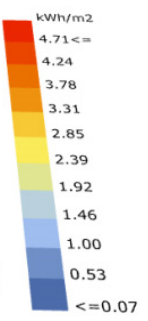

Radiation Analysis

1 JAN 1:00-31 DEC 24:00

(b.) Size and orientation.

Figure 10: Form optimization using Ladybug and Galapagos.

The above analysis, simulations and optimizations provide valuable design decision support. The goal was to achieve the optimum sustainable suburban transformation with the objective of human comfort in mind. The overall methodology is shown in fig. 11.

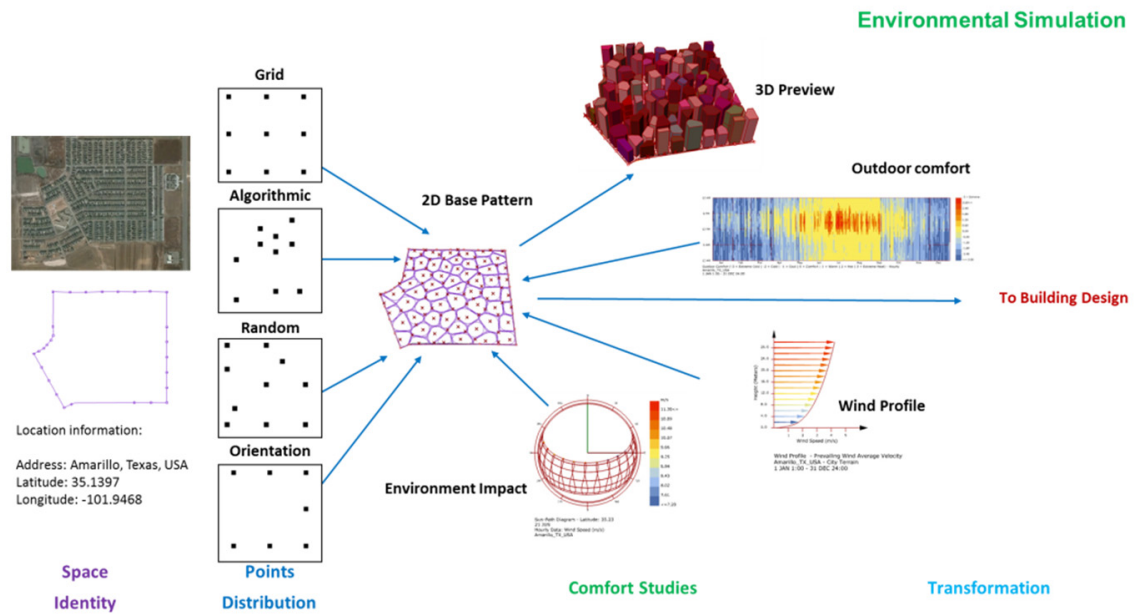

Figure 11: Simulation methodology. 
Simple optimizations with Galapagos were performed. A comparison analysis was carried out between the resulting case and the initial case. The findings and results were analysed to see how they influence the district form in terms of density of sites, pattern, orientation and also the building form in terms of type of foundation, plan, cluster, orientation. Future recommendations were drawn based on the findings and results.

\section{Future work}

While parametric designs have been largely explored for their capacity for futuristic form-making [21], including the work of Zaha Hadid Architects and other studios reviewed in "Digital Cities" [22], their great potential for improving performance and sustainability have been overlooked. Changes in the rain and snow patterns, along with other similar global warming effects, indicate that these must be put on the parametric design agenda. Although still on an experimental level, these tools are being used in search for optimized urban and building designs [23], such as energy-efficient solutions in façade design, optimal window sizing relative to lighting etc. The capability to run simulations with different input parameters is essential to differentiating and optimizing specific properties, which, in turn, is essential for changing the repetitive and sometimes monotonous or uninteresting nature of today's suburban landscape.

This paper is intended to revitalize existing suburbs and to offer new parametric design models of how new suburbs can be designed with the ecological design methods in mind from the very beginning of the design process for suburbs everywhere by proposing the use of parametric design and flexible models.

Natural directions for future research include more accurate optimizations and energy performance type of simulation for optimizing suburb and building geometry. In order to enhance the analysis of the visualized data and simulations, we plan to carry out the same analytic process in other locations, which we know experience opposite climatic conditions.

\section{Acknowledgement}

Many thanks to Paul Lukez for sharing his wisdom and knowledge about suburban architecture.

\section{References}

[1] Lukez, P., Suburban Transformations, Princeton Architectural Press: New York, 2007.

[2] Dunham-Jones, E., Williamson, J., Retrofitting Suburbia: Urban Design Solutions for Redesigning Suburbs.

[3] De Jong, J.K., New SubUrbanisms, Taylor and Francis: London, 2013.

[4] Schöning B., (ed.). Variations of Suburbanism: Approaching a Global Phenomenon. Ibidem-Verlag: Stuttgart, 2015. 
[5] Barnett, J., \& Beasley, L., Ecodesign for Cities and Suburbs. Island Press: Washington, 2015.

[6] Stanilov, K. \& Scheer, B.C., (eds.). Suburban Form: An International Perspective. Taylor and Francis: London, 2004.

[7] Harris, R. \& Larkham, P.J., (eds.). Changing suburbs: Foundation, Form and Function, Routledge: New York, 1999.

[8] Wheeler, S.M., Planning for Sustainability: Creating Livable, Equitable and Ecological Communities, $2^{\text {nd }}$ Edition. Routledge: New York, 2013.

[9] Porteous, C., The New Eco-Architecture: Alternatives from the Modern Movement. Taylor and Francis: London, 2013.

[10] Low, N., Gleeson, B., Green, R., \& Radovic, D., The Green City: Sustainable Homes, Sustainable Suburbs. Taylor and Francis: London, 2012.

[11] Brebbia, C.A. \& Pulselli, R., (eds). Eco-Architecture V Harmonisation between Architecture and Nature, WITPress: Southampton, 2015.

[12] Bohnacker, H., Gross, B. \& Laub, J., Generative Design: Visualize, Program, and Create with Processing, Princeton Architectural Press: New York, 2012.

[13] Schumacher, P., Parametricism - A New Global Style for Architecture and Urban Design. AD Architectural Design, 79(4), 2009.

[14] Woodbury, R., Elements of Parametric Design. Routledge: New York, 2010.

[15] Flueckiger, U.P., Land Arts of the American West. Journal of Architectural Education, 64(1), pp. 135-139, 2010.

[16] Harrist, G.L., Sustainable Architecture, A thesis in Architecture, Texas Tech University, College of Architecture.

[17] Morris, J.M., Capturing the Heart of Spirituality, A Spiritual Refuge Center in Amarillo, TX, A thesis in Architecture, Texas Tech University, College of Architecture.

[18] Harlan, C.B., Architecture as an Abstraction of Nature, Master of Architecture, Texas Tech University, College of Architecture.

[19] Atsuyuki, O., Boots, B., Siguhara, K. \& Nok Chiu, S., Spatial tessellations. Concepts and Applications of Voronoi Diagrams. 2nd Edition. Wiley \& Sons: Chichester, 2000.

[20] Roudsari, M., Pak, M. \& Smith, A., Ladybug: A Parametric Environmental Plugin for Grasshopper to Help Designers Create an EnvironmentallyConscious Design. Proc. of Int. Conf. of IBPSA, Chambery, France, 2014.

[21] Parametric Design: What's Gotten Lost Amid the Algorithms http://www.architectmagazine.com/design/parametric-design-whats-gotten -lost-amid-the-algorithms_o

[22] Leach, N., (ed). Digital Cities AD: Architectural Design. John Wiley \& Sons: London, 2009.

[23] Yi, Y.K., \& Kim, H., Agent-based geometry optimization with Genetic Algorithm (GA) for tall apartment's solar right, Solar Energy, 113, pp. 236$250,2015$. 